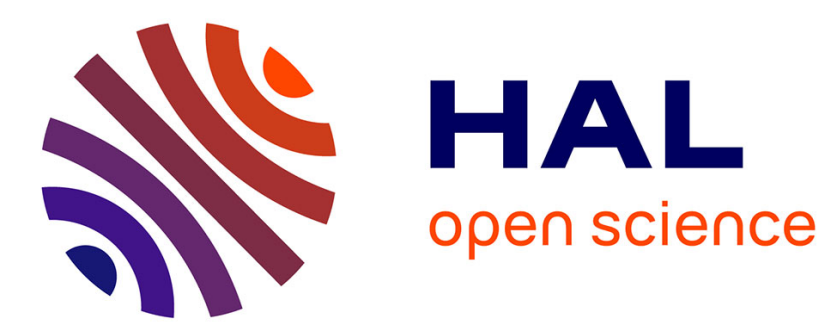

\title{
Aryl hydrocarbon receptor and liver fibrosis
}

Caroline Duval, Etienne Blanc, Xavier Coumoul

\section{To cite this version:}

Caroline Duval, Etienne Blanc, Xavier Coumoul. Aryl hydrocarbon receptor and liver fibrosis. Current Opinion in Toxicology, 2018, 8, pp.8-13. 10.1016/j.cotox.2017.11.010 . hal-02196325

\section{HAL Id: hal-02196325 \\ https://hal.science/hal-02196325}

Submitted on 27 Jul 2019

HAL is a multi-disciplinary open access archive for the deposit and dissemination of scientific research documents, whether they are published or not. The documents may come from teaching and research institutions in France or abroad, or from public or private research centers.
L'archive ouverte pluridisciplinaire HAL, est destinée au dépôt et à la diffusion de documents scientifiques de niveau recherche, publiés ou non, émanant des établissements d'enseignement et de recherche français ou étrangers, des laboratoires publics ou privés. 
Title: Aryl hydrocarbon Receptor and liver fibrosis

Authors: Caroline Duval ${ }^{*} \$$, Etienne Blanc ${ }^{*} \dagger$, Xavier Coumoul ${ }^{*} \dagger$

\section{$\$$ : Equal contributions}

\section{Affiliations :}

* INSERM UMR 1124, Toxicologie Pharmacologie et Signalisation cellulaire, 45 rue des SaintsPères, 75006 Paris, France

† Université Paris Descartes, Sorbonne Paris Cité, 45 rue des Saints-Pères, 75006 Paris, France

To whom correspondence should be addressed at Xavier Coumoul, INSERM UMR-S 1124, 45 rue des Saints-Pères, 75006 Paris, France, phone: +33142863359; fax: +33142863868; email: xavier.coumoul@parisdescartes.fr

Keywords: AhR; AhR Nuclear Translocator (ARNT); liver; TCDD; dioxin; fibrosis; hepatic stellate cells; NASH; HCC; PCB; hydrocarbons; chronic liver diseases; CLDs; cirrhosis; pentachlorophenol; agent orange; knock-out; vitamin $A$; transforming growth factor- $B$; furans; oxidative stress; reactive oxygen species; NTP; Nrf2; XME; cytochrome P450; extracellular matrix; ECM; MMP; metalloproteinases; metalloproteases; collagen; hyperhomocysteinemia; iron; lipoxin A4. 


\begin{abstract}
The concept of toxicant-associated liver disease (TALD) has recently emerged linking exposure to pollutants to the development of chronic liver diseases (CLD) including fibrosis. Among such pollutants, ligands of the Aryl hydrocarbon Receptor (AhR), a transcriptional factor involved in detoxification processes, have been suspected to trigger multiple mechanisms (oxidative stress, epithelial and mesenchymal transition) associated with the occurrence of such pathologies. However, AhR knockout-mice also could develop liver fibrosis, an observation which might first be described as a paradox. In this review, we will present the different mechanisms linking AhR ligands and CLD and provide a hypothesis to solve this paradox.
\end{abstract}




\section{Introduction}

Liver fibrosis is defined as a response to a sustained cell injury and chronic inflammation that leads to the activation of pro-fibrotic cells and the excessive deposition of extracellular matrix. While reversible, it often leads to fatal complications or increases the risk of hepatocellular carcinoma (HCC). To study the mechanisms which lead to this pathology, experimental animal models have been developed mostly implicating rodents, and can be chemically-induced, surgically-based, diet-based or genetically-modified [1]. Several types of etiologic factors have been identified such as alcohol consumption or viral exposure. However, the contribution of environmental causes such as exposure to persistent organic pollutants (POPs), has been recently documented (TALD: toxicant-associated liver disease) [2]. In this review, we will focus on the specific contribution of the Aryl hydrocarbon Receptor (AhR), which can bind some of these POPs, on the occurrence of liver fibrosis.

\section{AhR ligands, mechanism of action and functions (Figure 1)}

The AhR has been identified in the 90's as a xenobiotic receptor which detects many organic pollutants (some of them persistent) such as dioxins, furans, some polychlorinated biphenyls (PCBs) and polycyclic aromatic hydrocarbons and triggers a transcriptional program leading to the expression of xenobiotic metabolizing enzymes such as cytochromes P450 (CYP) or UDPglucuronosyltransferases (UGT), that metabolize the pre-cited ligands, favoring their elimination in wasting fluids (e.g. urine). This elegant mechanism of action (detection/metabolism/elimination) historically strengths the idea that the AhR displayed only one unique function, dedicated to the regulation of xenobiotic metabolism. However, the development of knock-out models in vertebrates and invertebrates led to the suspicion of alternative functions of this receptor. Endogenous ligands including tryptophan metabolites started to be identified [3]. During the 00's with the emergence of large-scale omics-based technologies, several teams started to decipher other AhR functions such as the regulation of the epithelial-mesenchymal transition (EMT associated to cell adhesion/migration, and to the regulated expression of epithelial/mesenchymal markers) [4-6]. Non-genomic pathways and complex interactions with nuclear receptors were then identified. Thus, the AhR appears to be a far more complex protein than initially expected $[4,6]$.

\section{Chemically-activated AhR and liver fibrosis}




\subsection{Epidemiological and animal models-based evidence}

Epidemiological studies reported previously a potential link between environmental or accidental exposure to dioxins or AhR ligands and CLDs. Studies on US veterans (Operation Ranch Hand) exposed to TCDD (2,3,7,8-TetraChloroDibenzo-p-Dioxin, a contaminant of Agent Orange), did not show any increase of the expected mortality compared to the overall population but they identified an increased number of deaths due to digestive diseases especially caused by CLDs such as cirrhosis (the highest grade of fibrosis) [7-9]. This was also observed in cohorts of workers potentially-exposed to dioxins (e.g. resulting from manipulation of pentachlorophenol) [10-12] or on accidently-exposed horses, which displayed centrilobular fibrosis as the most predominant liver lesion [13].

Animal models exposed to TCDD (and subsequently activating the AhR) were also reported to develop liver fibrosis [14-16]. For example, the US National Toxicology Program (NTP), a 2years study on TCDD or binary mixtures of dioxin-like compounds such as PCBs or furans, reveals a hepatotoxicity in several female rats, including liver fibrosis (mostly portal, sometimes centrilobular) [17-23].

\subsection{TCDD-activated AhR and oxidative stress (Figure 1)}

One of the first legitimated mechanisms that could link AhR ligands with liver fibrosis, is oxidative stress [24]. Indeed, TCDD is known to produce reactive oxygen species (ROS) through transcriptional and translational induction of CYP1 enzymes which catalyze uncoupling reactions [24]. Such a CYP-related oxidative stress mechanism is already firmly suspected in the chemically-induced $\mathrm{CCl}_{4}$ - experimental model of liver fibrosis as $\mathrm{CCl}_{4}$ is metabolized notably by cytochrome P450 2E1 (CYP2E1), leading to lipid peroxidation by the production of ROS. In addition, TCDD promotes a decreased glycolytic flux with a switch of pyruvate kinases, favoring the production of $\mathrm{NADPH}, \mathrm{H}^{+}$used by CYP-based catalytic reactions $[25,26]$. Furthermore, TCDD represses the level of expression of hepcidin (involved in the regulation of intracellular iron levels) which indirectly contributes to oxidative stress through iron-related Fenton reactions [27]. Moreover, a tight and complex interplay between the AhR and the Nrf2 signaling pathways (known to activate antioxidant enzymes) has been described, with direct consequences on TCDD-induced oxidative stress and fibrosis in the liver [28].

Over-production of ROS induces cell death (apoptosis/necrosis) and as a consequence, the release of pro-inflammatory and pro-fibrotic mediators by dying cells activates hepatic stellate 
cells (HSCs) which acquire a myofibroblastic phenotype (expressing alpha-smooth muscle actin (alpha-SMA), producing pro-fibrotic factors, e.g. TGF- $ß$, and components of the extracellular matrix such as collagens type I, III and IV; fibronectin and proteoglycans). Additionally, TCDD favors the recruitment of inflammatory cells and the development of a local inflammation in the liver through AhR interaction with inflammatory pathways further promoting ROS production as well as the activation of HSCs [29-31]. Beside, TCDD disrupts lipid metabolism in the liver promoting the production of triglycerides, cholesterol esters and phospholipids and the increased uptake and packaging of lipids [14,25,32]. Such deregulations associated with a local inflammation promote NASH and probably fibrosis $[14,16,33]$. In addition, alterations in lipid metabolism can lead also to lipotoxicity that has been shown to contribute to oxidative stress, local inflammation and subsequent liver damages [34].

\subsection{TCDD-activated AhR and EMT (Figure 1)}

We and others $[4-6,14,15,35,36]$ reported that the AhR regulates EMT through the induction of Slug and Snail, two transcription factors which down-regulate the expression of E-Cadherin, a critical transmembrane protein essential for the proper architecture of epithelia. Overexpression of such EMT regulators is reported for TCDD-treated cells but also in vivo, where such processes are demonstrated in parallel to the occurrence of liver fibrosis in mice, after only 2 weeks of sub-chronical exposure to high doses of TCDD (25 $\mu \mathrm{g} / \mathrm{kg}$, once a week) [15]. While EMT is a fundamental process for embryonic development (e.g. gastrulation), it is also suspected to participate to pathological processes such as the formation of metastatic cells or organ fibrosis (kidney and liver). The involvement of EMT in hepatocytes and biliary cells during the progression of CLDs, is nowadays challenged by several authors and it is legitimate to think that those cells might not undergo a complete EMT but still, could contribute to the activation of HSCs through perturbation of the liver microenvironment.

\subsection{TCDD-activated AhR and hepatic stellate cells (Figure 1)}

TCDD can activate HSCs both in vitro and in vivo with an over-expression of pro-fibrotic genes or pro-ECM-remodeling genes (matrix metalloproteinases, procollagens); however since the period of exposure was too short and despite the induction of pro-fibrotic markers, the authors did not observe a liver fibrosis [31,37]. Interestingly, in vitro and in vivo, the effect of TCDD on HSCs might be due to the activation of several signaling pathways (not only the 
classically-described AhR-ARNT signaling pathway); TCDD-induced proliferation of HSCs was indeed blocked by an inhibitor of the $\mathrm{PI} 3 \mathrm{~K}$, but not the production of monocyte chemoattractant protein-1 (MCP-1), which contributes to the development of a local inflammation $[29,30]$. Besides, TCDD might also favor intrahepatic coagulation and collagen deposit through the action of Protease Activated Receptor 1 (PAR-1), a coagulation receptor expressed by HSCs, whose activation promotes myofibroblast differentiation. Indeed, PAR-1deficient mice displays a less pronounced collagen deposit in the liver upon TCDD exposure [38].

\section{A contextual role of POPs}

The role of the AhR in the occurrence of liver fibrosis is also probably contextual depending on the influences of many parameters such as diet composition [14,27]. Indeed, iron promotes AhR-mediated hepatotoxicity as an iron-enriched diet potentiates TCDD-induced hepatotoxicity [27]. Recently, we demonstrated that a low dose of TCDD which do not lead to liver fibrosis per se (under a 6-week exposure protocol, $5 \mu \mathrm{g} / \mathrm{kg}$ once in a week), was able to trigger such phenomena in a high fat diet-induced NASH context [14]. Those studies highlight two important points to consider regarding the influence of POPs on the occurrence of liver

fibrosis: 1) the length of the POP exposure which is highly relevant to consider for persistent organic pollutants and 2) the combination of the POP exposure with other risk factors of liver fibrosis. Moreover, human western diets not only represent a significant source of fat but also contaminants (lipophilic organic pollutants). The view that xenobiotic AhR ligands promote liver fibrosis over a long period of exposure suggests that the AhR needs to be continuously activated to trigger such phenomena. This is consistent with the mode of action of POPs which can be stored in the liver (TCDD binds with a very high affinity in the catalytic site of CYP1A2 without any conversion) and exert their biochemical effects over long periods of time (the half-life of TCDD in humans is comprised between 7-8 years). Moreover, the adipose tissue slowly releases POPs, a phenomena which can impact the liver chronically [39].

\section{AhR and liver fibrosis in the absence of sustained activation by chemical ligands}

\subsection{AhR-KO mice and liver fibrosis}

The first experimental reports mentioning a potential link between the AhR and liver fibrosis, came from studies on AhR-knockout (KO) models. As initially demonstrated [40-42], a large 
majority of AhR-KO mice (81\%) develops hepatic portal fibrosis. Subsequent molecular studies showed that the absence of the AhR during mice development, leads to local increased expression of pro-fibrotic effectors such as transforming growth factor- $\beta 1$ and 3 (TGF- $\beta 1$ and 3) or TGF- $ß$ regulators such as Latent TGF-beta-binding protein-1 (LTBP-1) [36,43]. An increased number of apoptotic hepatocytes is also observed in AhR-KO mice [43]. Beyond the involvement of these hepatocytes, the role of vitamin A has been quickly underlined as its depletion in the diet of AhR-KO mice impairs the development of the fibrosis $[44,45]$ suggesting that HSCs (which store vitamin A and release it following their activation) could play a role in the development of fibrosis. Moreover, a down-regulation of cytochrome P450 2C39, a retinoic acid 4-hydroxylase, is observed in AhR-KO mice, contributing probably to the accumulation of vitamin A in the mouse liver and a subsequent higher activation of HSCs [4446].

The portal fibrosis described in AhR-KO mice could be analyzed as a paradox, as TCDD commonly described as an AhR agonist also promotes fibrosis (see §4). However, a decreased expression of the AhR at both mRNA and protein levels (and subsequently of the induction of CYP1), is observed in parallel to the progression towards CLDs in cirrhotic rats and human patients $[47,48]$, in support for a protective role of the AhR regarding liver fibrosis.

\subsection{Endogenous ligands of AhR and liver fibrosis: the paradox resolution}

Actually, a hypothesis can be easily drawn which reconciles this first-sight paradox: the AhR has been identified as a xenobiotic receptor but several recent studies demonstrated the existence of several endogenous ligands (like tryptophan metabolites) [3]. Such ligands are probably involved in liver development and homeostasis. Beyond this developmental role, the AhR has evolved as a xenobiotic receptor whose transient activation participates in the regulation of xenobiotic metabolism, an important detoxifying function which is significantly different from the ones regulated by the endogenous ligands and probably not toxic over short periods of activation. However, as both transcriptional programs are probably clearly distinct between both types of ligands as suggested by ChIP-on-ChIP experiments performed by the team of A. Puga, sustained xenobiotic-related AhR activation could disrupt homeostatic programs regulated by endogenous ligands as for example TCDD can be seen as a high affinity ligand, then highly competitive (figure 2) [49]. 
The diet could then represent an important contextual parameter as such endogenous ligands could be amino acids metabolites (e.g. tryptophan). Interestingly, alteration of the levels of amino acids has been associated with the promotion of liver fibrosis [50]. For instance, a highmethionine diet induces experimentally hyperhomocysteinemia (HHCy) and liver fibrosis in mice. Yao L et al. have shown that HHCy activates the AhR leading to an increase expression of CD36, the fatty acid (FA) transporter and subsequently to liver uptake of FA and steatosis. The authors suggest that this activation is linked to the production of lipoxin $A 4$, an endogenous ligand of the AhR and a metabolite of arachidonic acid [50].

\section{Conclusion}

Strong evidence supports a crucial role of a sustained AhR activation by pollutants in the development of liver fibrosis through direct regulation of pro-fibrotic processes such as oxidative stress, EMT or HSC activation. CLDs highly depend also on metabolic disruptions which can be triggered by TCDD (and other pollutants) [33], putting the dietary context as a central aspect in studying the deleterious effect of TCDD on fibrosis development.

Persistent organic pollutants are not the only "new" etiologic factors which lead to liver fibrosis. Other factors need to be considered such as gender or housing temperature [51]. Another interesting question is related to the models used to study liver fibrosis, mostly rodents; indeed, the use of complementary in vitro models could also be useful to define precisely the molecular mechanisms of action since new relevant hepatocellular models (HepaRG, 3D cell cultures) are now available [52]. Also, a better assessment of the role of the AhR in fibrosis with the development of new methodologies of quantification such as PicroSirius Red could be undertaken [53]. Finally, other animal models such as zebrafish, display liver metabolic alterations upon exposure to TCDD and could become relevant regarding their costs, to better understand the progression of CLDs [54].

While preventing or therapeutic protocols are now well documented, the identification of the xenobiotics and their mechanisms of action might represent an interesting outcome to decrease the incidence of CLDs including liver fibrosis. The persistence of molecules which could sustain the activation of the AhR in hepatocytes and of HSCs, appears as one important criteria to take into account. As such contaminants are also part of Western type diets (a "double-edge sword"), the prevention to eat such diets might be even more potent if taking 
into account the "contaminant factor" and a good way to change our habits regarding food consumption.

\section{Figure legends}

Figure 1: The AhR regulates a diversity of signaling pathways in hepatocytes and in hepatic stellate cells which can contribute to the development of liver fibrosis including epithelialmesenchymal transition, oxidative stress, secretion of extracellular matrix components and local inflammation.

Figure 2: The AhR is activated by endogenous ligands whose action can be potentially disrupted by the competitive binding of xenobiotics. 


\section{Bibliography}

1. Zoubek ME, Trautwein C, Strnad P: Reversal of liver fibrosis: From fiction to reality. Best Pract Res Clin Gastroenterol 2017, 31:129-141.

2. Joshi-Barve S, Kirpich I, Cave M, Marsano L, McClain C: Alcoholic, Nonalcoholic, and Toxicant-Associated Steatohepatitis: Mechanistic Similarities and Differences. - PubMed NCBI. 2015,

3. Guyot E, Chevallier A, Barouki R, Coumoul X: The AhR twist: ligand-dependent AhR signaling and pharmaco-toxicological implications. Drug Discov Today 2013, 18:479-486.

4. Diry M, Tomkiewicz C, Koehle C, Coumoul X, Bock KW, Barouki R, Transy C: Activation of the dioxin/aryl hydrocarbon receptor (AhR) modulates cell plasticity through a JNKdependent mechanism. Oncogene 2006, 25:5570-5574.

5. Linh-Chi B, Céline T, Stephane P, Aline C, Robert B, Xavier C: Regulation of Aquaporin 3 expression by the AhR pathway is critical to cell migration. Toxicol Sci Off J Soc Toxicol 2015, doi:10.1093/toxsci/kfv221.

6. Tomkiewicz C, Herry L, Bui L-C, Métayer C, Bourdeloux M, Barouki R, Coumoul X: The aryl hydrocarbon receptor regulates focal adhesion sites through a non-genomic FAK/Src pathway. Oncogene 2013, 32:1811-1820. $\left(^{*}\right)$

7. Yi S-W, Hong J-S, Ohrr H, Yi J-J: Agent Orange exposure and disease prevalence in Korean Vietnam veterans: the Korean veterans health study. Environ Res 2014, 133:56-65.

8. Yi S-W, Ryu S-Y, Ohrr H, Hong J-S: Agent Orange exposure and risk of death in Korean Vietnam veterans: Korean Veterans Health Study. Int J Epidemiol 2014, 43:1825-1834.

9. Michalek JE, Ketchum NS, Akhtar FZ: Postservice mortality of US Air Force veterans occupationally exposed to herbicides in Vietnam: 15-year follow-up. Am J Epidemiol 1998, 148:786-792.

10. Ramlow JM, Spadacene NW, Hoag SR, Stafford BA, Cartmill JB, Lerner PJ: Mortality in a cohort of pentachlorophenol manufacturing workers, 1940-1989. Am J Ind Med 1996, 30:180-194.

11. Pazderova-Vejlupková J, Lukás E, Nĕmcova M, Pícková J, Jirásek L: The development and prognosis of chronic intoxication by tetrachlordibenzo-p-dioxin in men. Arch Environ Health 1981, 36:5-11.

12. Ott MG, Olson RA, Cook RR, Bond GG: Cohort mortality study of chemical workers with potential exposure to the higher chlorinated dioxins. J Occup Med Off Publ Ind Med 
Assoc 1987, 29:422-429.

13. Kimbrough RD, Carter CD, Liddle JA, Cline RE: Epidemiology and pathology of a tetrachlorodibenzodioxin poisoning episode. Arch Environ Health 1977, 32:77-86.

14. Duval C, Teixeira-Clerc F, Leblanc AF, Touch S, Emond C, Guerre-Millo M, Lotersztajn S, Barouki R, Aggerbeck M, Coumoul X: Chronic Exposure to Low Doses of Dioxin Promotes Liver Fibrosis Development in the C57BL/6J Diet-Induced Obesity Mouse Model. Environ Health Perspect 2017, 125:428-436. (**)

15. Pierre S, Chevallier A, Teixeira-Clerc F, Ambolet-Camoit A, Bui L-C, Bats A-S, Fournet JC, Fernandez-Salguero P, Aggerbeck M, Lotersztajn S, et al.: Aryl hydrocarbon receptordependent induction of liver fibrosis by dioxin. Toxicol Sci Off J Soc Toxicol 2014, 137:114124. $(*)$

16. He J, Hu B, Shi X, Weidert ER, Lu P, Xu M, Huang M, Kelley EE, Xie W: Activation of the Aryl Hydrocarbon Receptor Sensitizes Mice to Nonalcoholic Steatohepatitis by Deactivating Mitochondrial Sirtuin Deacetylase Sirt3. Mol Cell Biol 2013, 33:2047-2055. ( ${ }^{*}$ )

17. National Toxicology Program: NTP toxicology and carcinogenesis studies of 3,3',4,4',5-pentachlorobiphenyl (PCB 126) (CAS No. 57465-28-8) in female Harlan SpragueDawley rats (Gavage Studies). Natl Toxicol Program Tech Rep Ser 2006,

18. National Toxicology Program: NTP technical report on the toxicology and carcinogenesis studies of 2,3,7,8-tetrachlorodibenzo-p-dioxin (TCDD) (CAS No. 1746-01-6) in female Harlan Sprague-Dawley rats (Gavage Studies). Natl Toxicol Program Tech Rep Ser 2006 ,

19. National Toxicology Program: NTP technical report on the toxicology and carcinogenesis studies of 2,3,7,8-tetrachlorodibenzo-p-dioxin (TCDD) (CAS No. 1746-01-6) in female Harlan Sprague-Dawley rats (Gavage Studies). Natl Toxicol Program Tech Rep Ser 2006 ,

20. National Toxicology Program: Toxicology and carcinogenesis studies of a binary mixture of 3,3',4,4',5-pentachlorobiphenyl (PCB 126) (Cas No. 57465-28-8) and 2,2',4,4',5,5'hexachlorobiphenyl (PCB 153) (CAS No. 35065-27-1) in female Harlan Sprague-Dawley rats (gavage studies). Natl Toxicol Program Tech Rep Ser 2006,

21. National Toxicology Program: Toxicology and carcinogenesis studies of $2,3,4,7,8-$ pentachlorodibenzofuran (PeCDF) (Cas No. 57117-31-4) in female Harlan Sprague-Dawley rats (gavage studies). Natl Toxicol Program Tech Rep Ser 2006, 
22. National Toxicology Program: Toxicology and carcinogenesis studies of a mixture of 2,3,7,8-tetrachlorodibenzo-p-dioxin (TCDD) (Cas No. 1746-01-6), 2,3,4,7,8pentachlorodibenzofuran (PeCDF) (Cas No. 57117-31-4), and 3,3',4,4',5pentachlorobiphenyl (PCB 126) (Cas No. 57465-28-8) in female Harlan Sprague-Dawley rats (gavage studies). Natl Toxicol Program Tech Rep Ser 2006,

23. National Toxicology Program: Toxicology and carcinogenesis studies of a binary mixture of 3,3',4,4',5-pentachlorobiphenyl (PCB 126) (Cas No. 57465-28-8) and 2,3',4,4',5pentachlorobiphenyl (PCB 118) (Cas No. 31508-00-6) in female Harlan Sprague-Dawley rats (gavage studies). Natl Toxicol Program Tech Rep Ser 2006,

24. Morel Y, Barouki R: Repression of gene expression by oxidative stress. Biochem J 1999, 342 Pt 3:481-496.

25. Nault R, Fader KA, Kirby MP, Ahmed S, Matthews J, Jones AD, Lunt SY, Zacharewski TR: Pyruvate Kinase Isoform Switching and Hepatic Metabolic Reprogramming by the Environmental Contaminant 2,3,7,8-Tetrachlorodibenzo-p-Dioxin. Toxicol Sci Off J Soc Toxicol 2016, 149:358-371. $\left({ }^{*}\right)$

26. Zhang J-X, Li D-Q, He AR, Motwani M, Vasiliou V, Eswaran J, Mishra L, Kumar R: Synergistic inhibition of hepatocellular carcinoma growth by cotargeting chromatin modifying enzymes and poly (ADP-ribose) polymerases. Hepatol Baltim Md 2012, 55:18401851.

27. Fader KA, Nault R, Kirby MP, Markous G, Matthews J, Zacharewski TR: Convergence of hepcidin deficiency, systemic iron overloading, heme accumulation, and REV-ERBa/ $\beta$ activation in aryl hydrocarbon receptor-elicited hepatotoxicity. Toxicol Appl Pharmacol 2017, 321:1-17.

28. Lu H, Cui W, Klaassen CD: Nrf2 protects against 2,3,7,8-tetrachlorodibenzo-p-dioxin (TCDD)-induced oxidative injury and steatohepatitis. Toxicol Appl Pharmacol 2011, 256:122135. $\left({ }^{*}\right)$

29. Harvey WA, Jurgensen K, Pu X, Lamb CL, Cornell KA, Clark RJ, Klocke C, Mitchell KA: Exposure to 2,3,7,8-tetrachlorodibenzo-p-dioxin (TCDD) increases human hepatic stellate cell activation. Toxicology 2016, 344-346:26-33. $\left({ }^{*}\right)$

30. Han M, Liu X, Liu S, Su G, Fan X, Chen J, Yuan Q, Xu G: 2,3,7,8-Tetrachlorodibenzo-pdioxin (TCDD) induces hepatic stellate cell (HSC) activation and liver fibrosis in C57BL6 mouse via activating Akt and NF-кB signaling pathways. Toxicol Lett 2017, 273:10-19. (*) 
31. Lamb CL, Cholico GN, Pu X, Hagler GD, Cornell KA, Mitchell KA: 2,3,7,8Tetrachlorodibenzo-p-dioxin (TCDD) increases necroinflammation and hepatic stellate cell activation but does not exacerbate experimental liver fibrosis in mice. Toxicol Appl Pharmacol 2016, 311:42-51.

32. Nault R, Fader KA, Lydic TA, Zacharewski TR: Lipidomic Evaluation of Aryl Hydrocarbon Receptor-Mediated Hepatic Steatosis in Male and Female Mice Elicited by 2,3,7,8Tetrachlorodibenzo-p-dioxin. Chem Res Toxicol 2017, 30:1060-1075. (*)

33. Angrish $M M$, Mets $B D$, Jones $A D$, Zacharewski TR: Dietary Fat Is a Lipid Source in 2,3,7,8-Tetrachlorodibenzo-p-Dioxin (TCDD)-Elicited Hepatic Steatosis in C57BL/6 Mice. Toxicol Sci 2012, 128:377-386. ( $\left.{ }^{* *}\right)$

34. Mota M, Banini BA, Cazanave SC, Sanyal AJ: Molecular mechanisms of lipotoxicity and glucotoxicity in nonalcoholic fatty liver disease. Metabolism 2016, 65:1049-1061.

35. Bui L-C, Tomkiewicz C, Chevallier A, Pierre S, Bats A-S, Mota S, Raingeaud J, Pierre J, Diry M, Transy C, et al.: Nedd9/Hef1/Cas-L mediates the effects of environmental pollutants on cell migration and plasticity. Oncogene $2009,28: 3642-3651$.

36. Corchero J, Martín-Partido G, Dallas SL, Fernández-Salguero PM: Liver portal fibrosis in dioxin receptor-null mice that overexpress the latent transforming growth factor-betabinding protein-1. Int J Exp Pathol 2004, 85:295-302. (*)

37. Lamb CL, Cholico GN, Perkins DE, Fewkes MT, Oxford JT, Lujan TJ, Morrill EE, Mitchell KA: Aryl Hydrocarbon Receptor Activation by TCDD Modulates Expression of Extracellular Matrix Remodeling Genes during Experimental Liver Fibrosis. BioMed Res Int 2016, 2016:5309328. $\left({ }^{*}\right)$

38. Nault R, Fader KA, Kopec AK, Harkema JR, Zacharewski TR, Luyendyk JP: From the Cover: Coagulation-Driven Hepatic Fibrosis Requires Protease Activated Receptor-1 (PAR-1) in a Mouse Model of TCDD-Elicited Steatohepatitis. Toxicol Sci Off J Soc Toxicol 2016, 154:381-391.

39. Kim M-J, Marchand P, Henegar C, Antignac J-P, Alili R, Poitou C, Bouillot J-L, Basdevant A, Le Bizec B, Barouki R, et al.: Fate and Complex Pathogenic Effects of Dioxins and Polychlorinated Biphenyls in Obese Subjects before and after Drastic Weight Loss. Environ Health Perspect 2010, 119:377-383. $\left({ }^{* *}\right)$

40. Fernandez-Salguero P, Pineau T, Hilbert DM, McPhail T, Lee SS, Kimura S, Nebert DW, Rudikoff S, Ward JM, Gonzalez FJ: Immune system impairment and hepatic fibrosis in mice 
lacking the dioxin-binding Ah receptor. Science 1995, 268:722-726. (**)

41. Fernandez-Salguero PM, Ward JM, Sundberg JP, Gonzalez FJ: Lesions of arylhydrocarbon receptor-deficient mice. Vet Pathol 1997, 34:605-614.

42. Schmidt JV, Su GH, Reddy JK, Simon MC, Bradfield CA: Characterization of a murine Ahr null allele: involvement of the Ah receptor in hepatic growth and development. Proc Natl Acad Sci U S A 1996, 93:6731-6736. (**)

43. Zaher H, Fernandez-Salguero PM, Letterio J, Sheikh MS, Fornace AJ, Roberts AB, Gonzalez FJ: The involvement of aryl hydrocarbon receptor in the activation of transforming growth factor-beta and apoptosis. Mol Pharmacol 1998, 54:313-321.

44. Andreola F, Fernandez-Salguero PM, Chiantore MV, Petkovich MP, Gonzalez FJ, De Luca LM: Aryl hydrocarbon receptor knockout mice (AHR-/-) exhibit liver retinoid accumulation and reduced retinoic acid metabolism. Cancer Res 1997, 57:2835-2838.

45. Andreola F, Calvisi DF, Elizondo G, Jakowlew SB, Mariano J, Gonzalez FJ, De Luca LM: Reversal of liver fibrosis in aryl hydrocarbon receptor null mice by dietary vitamin A depletion. Hepatol Baltim Md 2004, 39:157-166.

46. Andreola F, Hayhurst GP, Luo G, Ferguson SS, Gonzalez FJ, Goldstein JA, De Luca LM: Mouse liver CYP2C39 is a novel retinoic acid 4-hydroxylase. Its down-regulation offers a molecular basis for liver retinoid accumulation and fibrosis in aryl hydrocarbon receptornull mice. J Biol Chem 2004, 279:3434-3438.

47. Floreani M, De Martin S, Gabbia D, Barbierato M, Nassi A, Mescoli C, Orlando R, Bova S, Angeli P, Gola E, et al.: Severe liver cirrhosis markedly reduces AhR-mediated induction of cytochrome P450 in rats by decreasing the transcription of target genes. PloS One 2013, 8:e61983.

48. Hanada K, Nakai K, Tanaka H, Suzuki F, Kumada H, Ohno Y, Ozawa S, Ogata H: Effect of nuclear receptor downregulation on hepatic expression of cytochrome P450 and transporters in chronic hepatitis $\mathrm{C}$ in association with fibrosis development. Drug Metab Pharmacokinet 2012, 27:301-306.

49. Sartor MA, Schnekenburger M, Marlowe JL, Reichard JF, Wang Y, Fan Y, Ma C, Karyala S, Halbleib D, Liu X, et al.: Genomewide analysis of aryl hydrocarbon receptor binding targets reveals an extensive array of gene clusters that control morphogenetic and developmental programs. Environ Health Perspect 2009, 117:1139-1146. $\left(^{*}\right)$

50. Yao L, Wang C, Zhang X, Peng L, Liu W, Zhang X, Liu Y, He J, Jiang C, Ai D, et al.: 
Hyperhomocysteinemia activates the aryl hydrocarbon receptor/CD36 pathway to promote hepatic steatosis in mice. Hepatol Baltim Md 2016, 64:92-105.

51. Ganeshan K, Chawla A: Warming the mouse to model human diseases. Nat Rev Endocrinol 2017, 13:458-465.

52. Attignon EA, Leblanc AF, Le-Grand B, Duval C, Aggerbeck M, Rouach H, Blanc EB: Novel roles for AhR and ARNT in the regulation of alcohol dehydrogenases in human hepatic cells. Arch Toxicol 2017, 91:313-324. ( $\left.{ }^{*}\right)$

53. Nault R, Colbry D, Brandenberger C, Harkema JR, Zacharewski TR: Development of a computational high-throughput tool for the quantitative examination of dose-dependent histological features. Toxicol Pathol 2015, 43:366-375.

54. Liu Q, Spitsbergen JM, Cariou R, Huang C-Y, Jiang N, Goetz G, Hutz RJ, Tonellato PJ, Carvan MJ: Histopathologic alterations associated with global gene expression due to chronic dietary TCDD exposure in juvenile zebrafish. PloS One 2014, 9:e100910.

\section{Conflict of interest:}

The authors declare no conflict of interest.

\section{Acknowledgments:}

This work was supported by funds from the Institut National de la Santé et de la Recherche Médicale (INSERM), the Institut National du Cancer (INCA) and the University Paris Descartes. We thank Dr. Lawrence Aggerbeck for critical reading of the manuscript. 


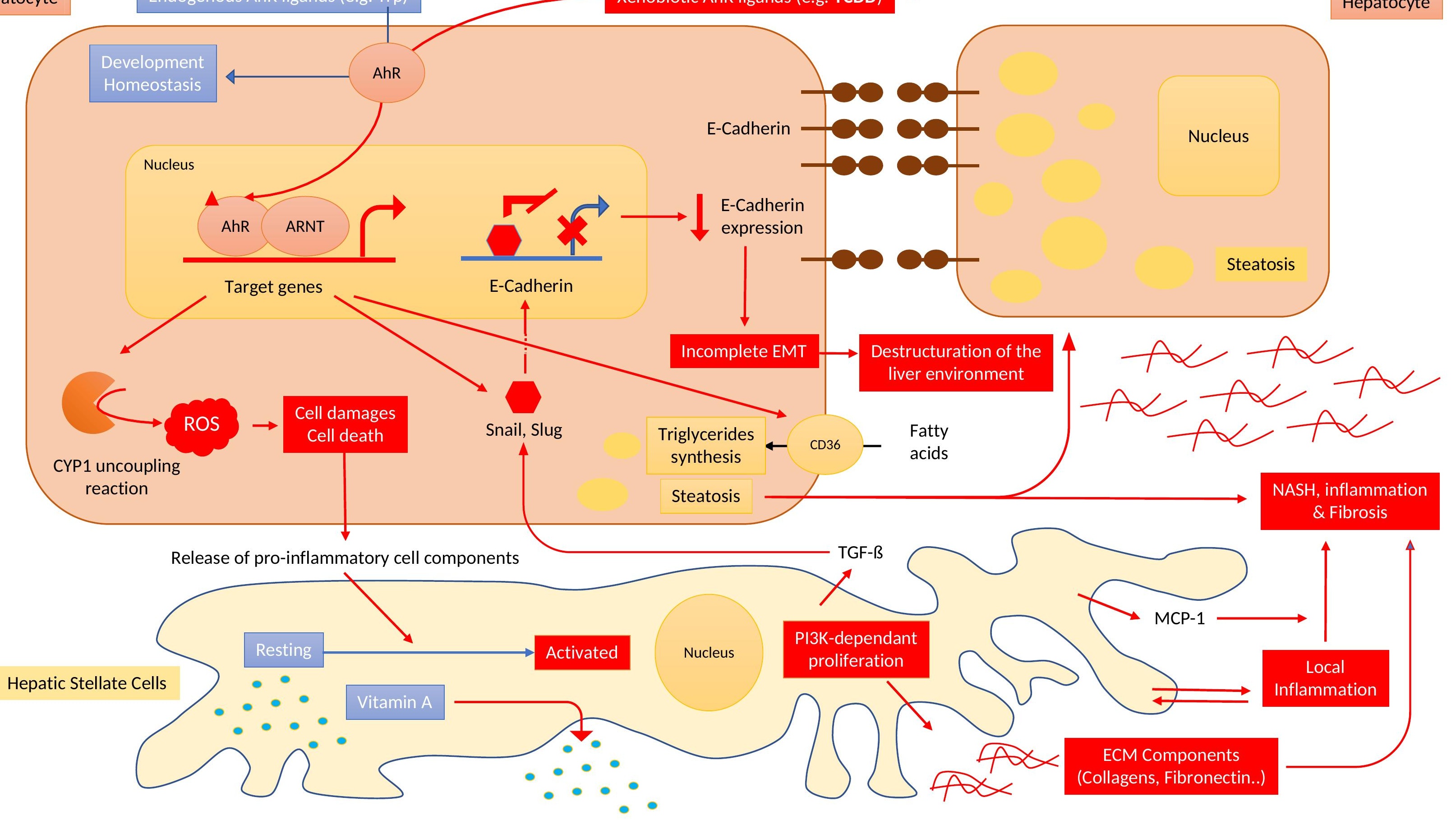


$\nmid$ Endogenous AhR ligands (e.g. Trp)

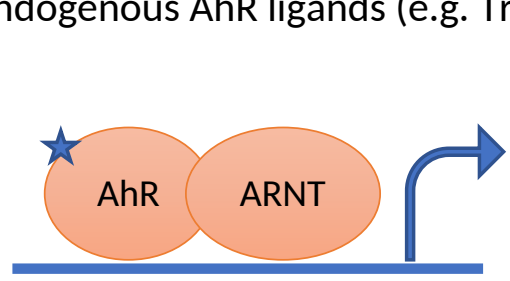

Development Homeostasis

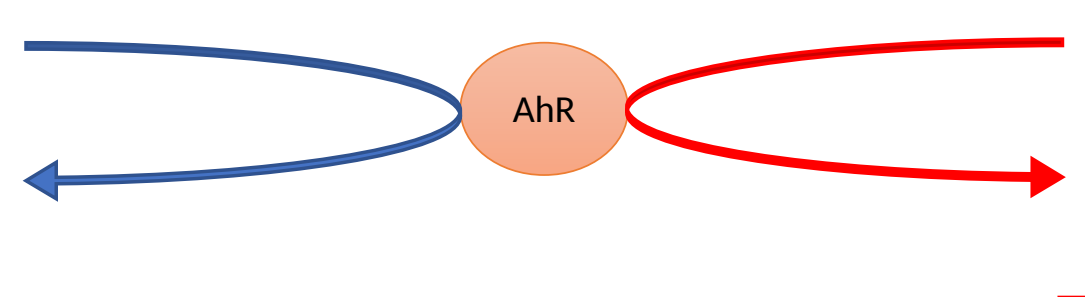

$\Delta$ Xenobiotic AhR ligands (e.g. TCDD)

DISRUPTION

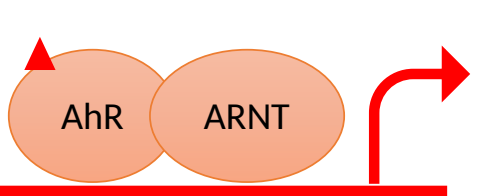

Xenobiotic

Metabolism 